05

\title{
Исследование механизмов изменения степени униполярности при термической обработке сильно легированных кристаллов $\mathrm{LiNbO}_{3}: \mathrm{ZnO}$
}

\section{(C) М.Н. Палатников, В.А. Сандлер, Н.В. Сидоров, О.В. Макарова}

Институт химии и технологии редких элементов и минерального сырья им. И.В. Тананаева, Федеральный исследовательский центр „Кольский научный центр РАН“, 184209 Апатиты, Россия e-mail: palat_mn@chemy.kolasc.net.ru

Поступило в Редакцию13 фревраля 2018 г. В окончательной редакции 21 января 2020 г. Принято к публикации 4 фревраля 2020 г.

\begin{abstract}
Путем сравнения с температурным поведением номинально чистых кристаллов $\mathrm{LiNbO}_{3}$ конгруэнтного состава рассмотрены феноменологические механизмы повышения униполярности при термической обработке в условиях короткого замыкания сильно легированных кристаллов $\mathrm{LiNbO}_{3}: \mathrm{ZnO}$. Показано, что увеличение униполярности и соответственно процесс исчезновения доменной структуры в сильно легированных кристаллах $\mathrm{LiNbO}_{3}: \mathrm{ZnO}$ запускается термическим распадом заряженных полярных кластеров, стабилизирующих доменные границы. Процесс распада полярных кластеров сопровождался резкой скачкообразной инжекцией дополнительных носителей заряда (катионов $\mathrm{Li}^{+}$). Вследствие этого проводимость кристаллов $\mathrm{LiNbO}_{3}: \mathrm{ZnO}$ при температуре выше $800 \mathrm{~K}$ на порядок больше, чем у номинально чистых кристаллов $\mathrm{LiNbO}_{3}$ конгруэнтного состава. Это приводит к распаду доменной структуры в кристаллах $\mathrm{LiNbO}_{3}: \mathrm{ZnO}$ в отличие от кристаллов $\mathrm{LiNbO}_{3}$ конгруэнтного состава.
\end{abstract}

Ключевые слова: кристаллы, ниобат лития, легирование, статический пьезоэлектрический эффект, униполярность, домены, полярные кластеры.

DOI: $10.21883 /$ JTF.2020.08.49539.69-18

\section{Введение}

Кристалл ниобата лития $\left(\mathrm{LiNbO}_{3}\right)$ - многолетний центр притяжения интересов специалистов интегральной и нелинейной оптики, акустоэлектроники, квантовой электроники, физики твердого тела $[1,2]$. Интерес к исследованию сильно легированных кристаллов $\mathrm{LiNbO}_{3}: \mathrm{ZnO}(\sim 4.0-9.0 \mathrm{~mol} . \% \mathrm{ZnO}$ в расплаве $)$ в первую очередь обусловлен высокой стойкостью к оптическому повреждению [3].

В кристаллах $\mathrm{LiNbO}_{3}$ известно существование так называемых „упрямых“ доменов, не исчезающих при переключении поляризации и представляющих собой клиновидные несквозные домены с заряженными косыми стенками [4]. Монодоменизация выращенных кристаллов ниобата лития не приводит к идеальной униполярности, и в результате в объеме монодоменизированного кристалла могут оставаться антипараллельные „упрямые“ домены. Процесс монодоменизации представляет собой охлаждение кристалла в постоянном электрическом поле от температур, несколько превышающих точку Кюри $T_{\mathrm{C}} \sim 1400-1450 \mathrm{~K}$ и не слишком отличающихся от области плавления. При этом ионная проводимость кристалла по $\mathrm{Li}^{+}$превышает $10^{-4}(\Omega \cdot \mathrm{cm})^{-1}$ и в электрическом поле фактически происходит твердофазный электролиз кристалла $\mathrm{LiNbO}_{3}$. В этих условиях электроды, полностью обратимые по $\mathrm{Li}^{+}$, неосуществимы, что приводит к появлению градиентов концентрации основных компонентов в объеме кристалла и соответственно к образованию структурных дефектов, которые могут стабилизировать „упрямую“ доменную структуру. Кроме того, в сильно легированных кристаллах $\mathrm{LiNbO}_{3}$, таких как $\mathrm{LiNbO}_{3}: \mathrm{ZnO}$, формируются полярные кластеры, образованные локализованными вдоль полярной оси примесными и собственными дефектами [3]. Подобные полярные кластеры могут дополнительно стабилизировать доменную структуру кристаллов $\mathrm{LiNbO}_{3}: \mathrm{ZnO}$ по сравнению с номинально чистыми кристаллами $\mathrm{LiNbO}_{3}$.

В настоящей работе в широком интервале температур $(\sim 350-900 \mathrm{~K})$ сравниваются проводимость и диэлектрическая проницаемость, а также изменение степени униполярности при термической обработке исследованных ранее сильно легированных кристаллов $\mathrm{LiNbO}_{3}: \mathrm{ZnO}$ и номинально чистых кристаллов $\mathrm{LiNbO}_{3}$ конгруэнтного состава. Проведена оценка возможных механизмов изменения степени униполярности сильно легированных кристаллов $\mathrm{LiNbO}_{3}: \mathrm{ZnO}$, связанных со скачкообразными аномалиями на температурных зависимостях диэлектрической проницаемости и проводимости в области температур $\sim 800 \mathrm{~K}$.

\section{Методика эксперимента}

Гранулированная шихта ниобата лития с высокой насыпной плотностью $\left(\sim 3.4 \mathrm{~g} / \mathrm{cm}^{3}\right)$ для выращивания кри- 
сталлов $\mathrm{LiNbO}_{3}$ и $\mathrm{LiNbO}_{3}: \mathrm{ZnO}$ получена тщательным смешением $\mathrm{Nb}_{2} \mathrm{O}_{5}-\mathrm{Li}_{2} \mathrm{CO}_{3}$ или $\mathrm{Nb}_{2} \mathrm{O}_{5}-\mathrm{ZnO}-\mathrm{Li}_{2} \mathrm{CO}_{3} \mathrm{c}$ последующим высокотемпературным спеканием методом синтеза-грануляции [5]. Отношение $\mathrm{Li}_{2} \mathrm{O} / \mathrm{Nb}_{2} \mathrm{O}_{5}$ в исходной смеси соответствовало составу конгруэнтного плавления ( 0.945). Кристаллы $\mathrm{LiNbO}_{3}$ и $\mathrm{LiNbO}_{3}: \mathrm{ZnO}$ диаметром $40 \mathrm{~mm}$ и длиной цилиндрической части $\sim 35-40 \mathrm{~mm}$ были выращены в направлении (001) методом Чохральского из Рt-тиглей диаметром $75 \mathrm{~mm}$ в воздушной атмосфере. Выращивание производилось на ростовых установках индукционного типа, оснащенных системой автоматического контроля диаметра кристалла. С целью снятия термоупругих напряжений все выращенные кристаллы подвергались термической обработке при $T=1473 \mathrm{~K}$ в течение $24 \mathrm{~h}$. Кристаллы были монодоменизированы методом высокотемпературного электродиффузионного отжига (ВТЭДО) путем приложения постоянного электрического поля при охлаждении кристалла со скоростью $20 \mathrm{~K} / \mathrm{h}$ в температурном интервале $\sim 1570-1170 \mathrm{~K}$. Контроль степени монодоменности осуществлялся методом анализа частотной зависимости электрического импеданса и путем определения величины статического пьезомодуля $\left(d_{333 s}\right)$ кристаллической були.

Исследования дисперсии диэлектрических свойств и проводимости кристаллов $\mathrm{LiNbO}_{3}$ выполнены в диапазоне частот $20 \mathrm{~Hz}-1 \mathrm{MHz}$ с помощью измерителя импеданса Solartron 1260. Для измерений на фиксированных частотах использован измеритель иммитанса Е7-20. Держатель образцов представлял собой симметричную коаксиальную линию с плоским и игольчатым Pt-контактами на изоляторах из лейкосапфира. Конструкция держателя обеспечивала пренебрежимо малые значения монтажных реактивных параметров и собственной параллельной проводимости. Система термостатирования в диапазоне $\sim 300-1000 \mathrm{~K}$ обеспечивала стабильность температуры $\pm 0.1 \mathrm{~K}$. Для измерения температуры образцов была использована дифференциальная термопара хромель/алюмель с индивидуальной градуировкой по реперным точкам стандарта МПТШ-90. Опорный спай термопары стабилизировался тающим льдом. ЭДС термопары измерялась универсальным вольтметром В7-78/1 с погрешностью $\pm 0.5 \mu \mathrm{V}$.

Образцы для исследований представляли собой плоскопараллельные пластины с размерами $\sim 6 \times 8 \times 1 \mathrm{~mm}$ $z$-ориентации. На подготовленные поверхности образцов методом магнетронного распыления Pt-мишени на постоянном токе в среде $\operatorname{Ar}\left(p_{\mathrm{Ar}} \approx 1 \cdot 10^{-5} \mathrm{~Pa}\right)$ с предварительной ионной очисткой были нанесены Pt-электроды.

Значения пьезоэлектрического модуля $d_{333}$ получены прямыми измерениями поляризационного заряда, индуцированного статической механической нагрузкой образца указанной геометрии. Для измерения величины поляризационного заряда использовали электрометрический измеритель Keithley 6514. Нагрузка на образец создавалась методом ступенчатого нагружения с помо- щью восьми одинаковых грузов весом $\sim 8.5 \mathrm{~N}$ каждый, действующих в направлении $z$.

\section{Результаты и обсуждение}

Ранее в работах [6-10] сообщалось об аномальных температурных зависимостях диэлектрических свойств и проводимости кристаллов $\mathrm{LiNbO}_{3}: \mathrm{ZnO}$, в которых при температуре $T^{*} \approx 800 \pm 10 \mathrm{~K}$ наблюдалось скачкообразное увеличение проводимости и диэлектрической проницаемости. При этом в широком диапазоне температур как ниже, так и выше $T^{*}$ зависимость $\sigma(T)$ следует закону Аррениуса со значением энтальпии активации проводимости $H_{a} \approx 1.2-1.3 \mathrm{eV}$ [6-10], характерным для ионной проводимости по $\mathrm{Li}^{+}$в структуре $\mathrm{LiNbO}_{3}$ [11]. Было показано, что наблюдающаяся при $T>T^{*}$ низкочастотная диэлектрическая дисперсия обусловлена вкладом высокой ионной проводимости в измеренные значения $\varepsilon^{\prime}\{$ jite6-10. Кроме того, как в полидоменных, так и в монодоменизированных кристаллах $\mathrm{LiNbO}_{3}: \mathrm{ZnO}$ в результате высокотемпературного отжига в условиях короткого замыкания было обнаружено возникновение или (для монодоменизированных кристаллов $\mathrm{LiNbO}_{3}: \mathrm{ZnO}$ ) существенное увеличение спонтанной униполярности [6-10]. Значение измеренного в статическом режиме пьезомодуля $d_{333 s}$ для исходно полидоменного кристалла $\mathrm{LiNbO}_{3}: \mathrm{ZnO}$, подвергнутого отжигу в условиях короткого замыкания, достигало величины $\sim 16.2 \cdot 10^{-12} \mathrm{C} / \mathrm{N}$, что превышает максимальные значения пьезомодуля $d_{333}$, приводимые в справочной литературе для монодоменизированных кристаллов $\mathrm{LiNbO}_{3}$, а также значение $d_{333}$ для принудительно монодоменизированных кристаллов $\mathrm{LiNbO}_{3}: \mathrm{ZnO}[6,7,10]$. C точки зрения статического пьезоэлектрического эффекта, подобное состояние исходно полидоменного кристалла $\mathrm{LiNbO}_{3}: \mathrm{ZnO}$ можно считать близким к монодоменному и, следовательно, метастабильным.

В то же время номинально чистые кристаллы $\mathrm{LiNbO}_{3}$ конгруэнтного состава как исходно полидоменные, так и подвергнутые монодоменизации, по крайней мере при температурах меньше $\sim 900 \mathrm{~K}$, не испытывают существенных аномальных особенностей в температурном поведении диэлектрических свойств и проводимости (рис. 1).

В широком диапазоне температур $(\sim 600-900 \mathrm{~K})$ зависимость $\sigma(T)$ следует закону Аррениуса с одним и тем же значением энтальпии активации проводимости $H_{a} \approx 1.28 \mathrm{eV}$, характерным для ионной проводимости по $\mathrm{Li}^{+}$[11] (рис. 1). При более низких температурах энтальпия активации проводимости $H_{a} \approx 0.58 \mathrm{eV}$, что соответствует энергии активации поляронов в кристаллах $\mathrm{LiNbO}_{3}$ [12] (рис. 1,a). При $T \sim 650-720 \mathrm{~K}$ на зависимостях $\varepsilon^{\prime}(T)$ наблюдаются размытые горбообразные аномалии, очевидно, релаксационной природы: их температуры смещаются вверх при увеличении частоты 

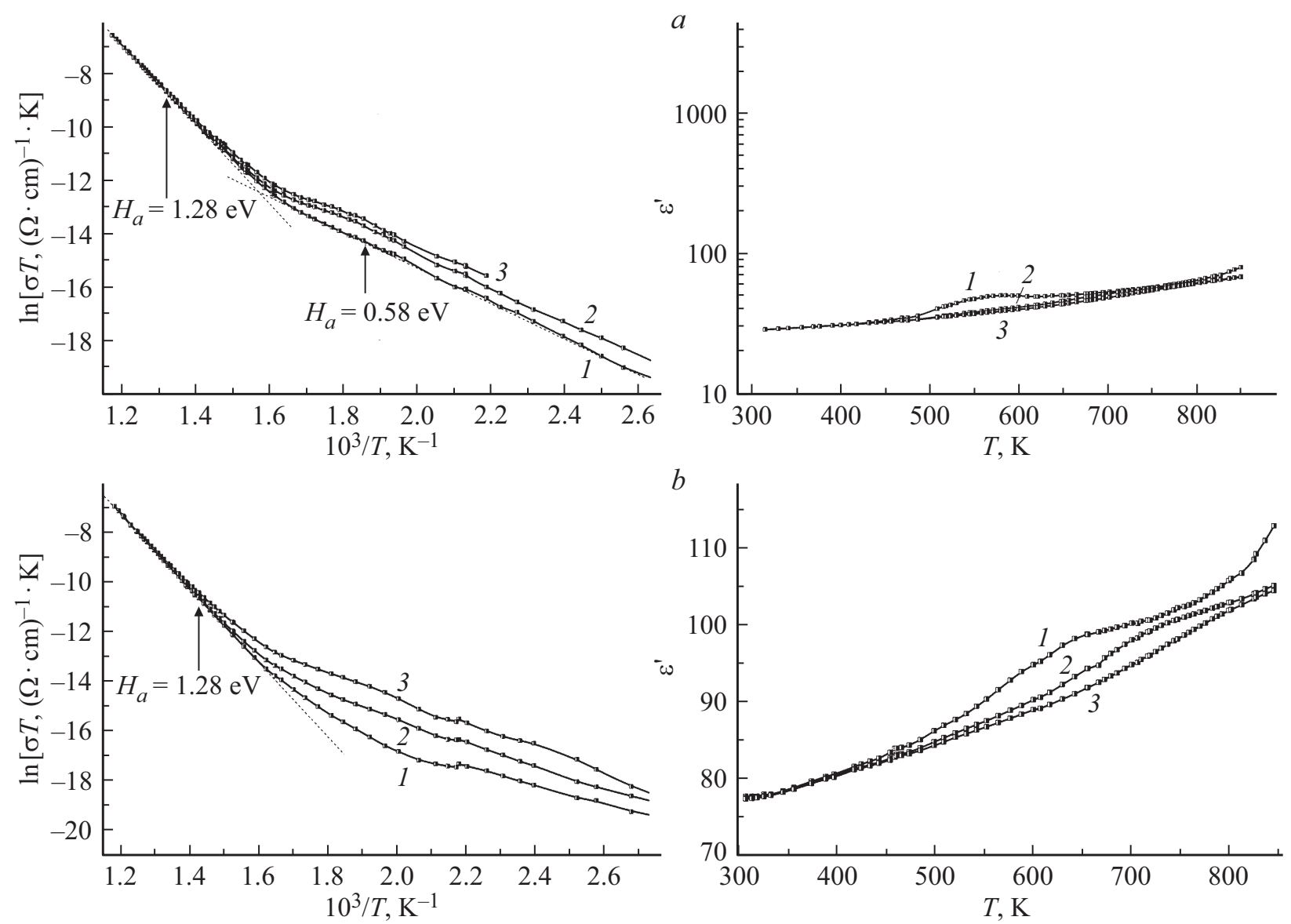

Рис. 1. Характерные температурные зависимости удельной проводимости полидоменных $(a)$ и монодоменизированных $(b)$ номинально чистых кристаллов $\mathrm{LiNbO}_{3}$ конгруэнтного состава, $z$-ориентация. $1-100 \mathrm{~Hz}, 2-1 \mathrm{kHz}, 3-10 \mathrm{kHz}$.

измерительного поля и практически исчезают при частоте $10 \mathrm{kHz}$ (рис. 1$)$.

Была исследована дисперсия комплексного импеданса кристаллов $\mathrm{LiNbO}_{3}$. Как известно [13], анализ диаграмм импеданса или адмиттанса позволяет корректно выделить вклад объемной проводимости в результаты измерений, а также получить температурные зависимости статической удельной проводимости $\sigma_{s v}(T)$ и времени релаксации объемной проводимости образцов $\tau_{v}(T)$. Характерный вид диаграмм импеданса как исходно полидоменного, так и подвергнутого монодоменизации кристалла $\mathrm{LiNbO}_{3}$-ориентации приведен на рис. 2 . В исследованном интервале температур как для исходно полидоменных, так и для подвергнутых монодоменизации номинально чистых кристаллов $\mathrm{LiNbO}_{3}$ конгруэнтного состава наблюдается один хорошо разрешенный релаксационный процесс дебаевского типа, причем эффекты поляризации электродов [14] практически не проявляются (рис. 2).

В результате анализа [14] диаграмм импеданса исходно полидоменного и подвергнутого монодоменизации кристаллов $\mathrm{LiNbO}_{3}$, полученных при различных температурах, построены зависимости статической проводимости $\sigma_{s v}(T)$ и времени релаксации $\tau_{v}(T)$, приведенные на рис. 3. Обработка диаграмм импеданса, в частности, позволяет уточнить энтальпию активации проводимости $H_{a}$ и рассчитать значения транспортной $\left(H_{m}\right)$ и френкелевской $\left(H_{F}\right)$ энтальпий [14]. Как известно, энтальпия активации ионной проводимости представляет собой сумму двух вкладов:

$$
H_{a}=H_{m}+\frac{1}{2} H_{F}
$$

Вид температурных зависимостей статической удельной проводимости $\sigma_{s v}(T) \mathrm{LiNbO}_{3}$ конгруэнтного состава удовлетворяет закону Аррениуса:

$$
\sigma_{s v}(T)=A_{0} \exp \left(-\frac{H_{a}}{k T}\right)
$$

где $A_{0}$ - предэкспоненциальный множитель, $H_{a}-$ энтальпия активации проводимости, $k-$ постоянная Больцмана. Зависимость $\tau(T)$ также удовлетворяет закону Аррениуса:

$$
\tau=\tau_{0} \exp \left(\frac{H_{m}}{k T}\right),
$$

где $\tau_{0}-$ предэкспоненциальный множитель, близкий к значению периода тепловых колебаний ионов, $H_{m}-$ 

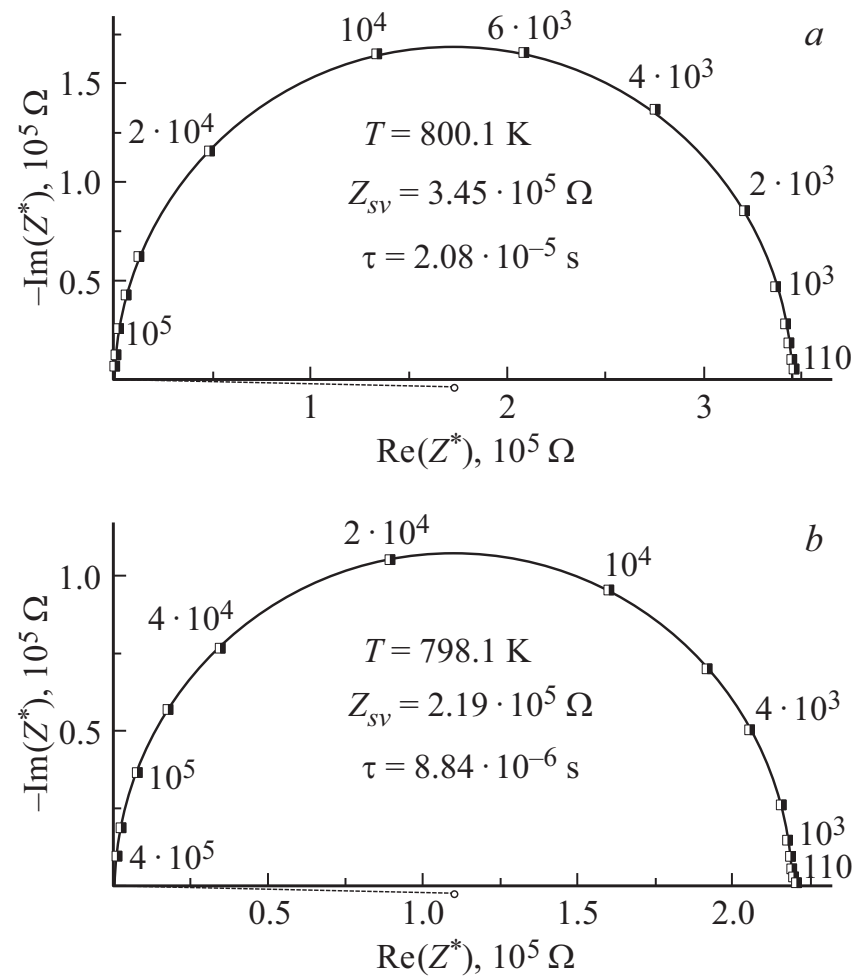

Рис. 2. Характерные диаграммы импеданса полидоменного (a) и монодоменизированного $(b)$ номинально чистого кристалла $\mathrm{LiNbO}_{3}$ конгруэнтного состава в диапазоне температур $\sim 600-900 \mathrm{~K}, z$-ориентация. Частоты измерительного поля указаны на рисунке в $\mathrm{Hz}$.

транспортная энтальпия. Анализ зависимостей (1)-(3) показал, что, как и полагается ионным проводникам, $H_{a}>H_{m}$. В то же время в широком интервале температур энтальпия образования дефектов по Френкелю для монодоменизированного кристалла невелика $\left(H_{F} \approx 0.16 \mathrm{eV}\right)$ по сравнению с таковой для исходно полидоменного кристалла $\mathrm{LiNbO}_{3}\left(H_{F} \approx 0.24 \mathrm{eV}\right)$, что является еще одним подтверждением более высокой концентрации точечных дефектов структуры в кристалле $\mathrm{LiNbO}_{3}$, подвергнутом процедуре монодоменизации, т. е. поскольку значение $H_{F}$ мало, осуществление ионного транспорта происходит без образования дополнительных точечных дефектов. Для монодоменизированного кристалла $\mathrm{LiNbO}_{3}$ характерно то, что в отличие от полидоменного при $T>600 \mathrm{~K}$ энтальпия активации проводимости на фиксированных частотах и статической проводимости имеет одно и то же численное значение $\left(H_{a}=1.28 \mathrm{eV}\right)$, что может служить еще одним подтверждением его более высокой дефектности (рис. 1 и 3).

С целью проверки влияния высокотемпературного отжига в условиях короткого замыкания на униполярность при комнатной температуре выполнены измерения статического пьезоэлектрического эффекта исходно полидоменного кристалла $\mathrm{LiNbO}_{3}$ и монодоменизированного кристалла $\mathrm{LiNbO}_{3}$ (рис. 4). Для кристаллов
$\mathrm{LiNbO}_{3}: \mathrm{ZnO}$ эти исследования тщательно выполнены в работах [6-10]. Основная идея этих экспериментов состоит в том, что в статических условиях измеренное значение пьезоэлектрического модуля (в геометрии $\left.d_{333 s}\right)$ линейно зависит от степени униполярности образца $x i$ [6-10]. Измерения по определению прямого пьезоэффекта при малой проводимости $\mathrm{LiNbO}_{3}$ при $T_{\text {room }}$ можно считать надежным и достаточно чувствительным „индикатором““ изменений доменной структуры образца.

На рис. 4 отчетливо видно, что отжиг в условиях короткого замыкания исходно полидоменного кристалла $\mathrm{LiNbO}_{3}$ конгруэнтного состава не привел к повышению степени его униполярности $\left(d_{333} \approx 0\right)$ (рис. 4 , кривая 1$)$. Для принудительно монодоменизированного кристалла $\mathrm{LiNbO}_{3}$ конгруэнтного состава униполярность также практически не изменилась (рис. 4, кривая 2). После отжига для него значение $d_{333}$ увеличилось с $\sim 9.71 \cdot 10^{-12}$ (не приведено на рис. 4) до $\sim 9.74 \cdot 10^{-12} \mathrm{C} / \mathrm{N}$, что соответствует среднему диапазону значений $d_{333}$ для кристалла $\mathrm{LiNbO}_{3}$ [15]. При этом увеличение $d_{333}$ на $0.03 \cdot 10^{-12} \mathrm{C} / \mathrm{N}$ укладывается в диапазон ошибки измерений. В то же время для исходно полидоменных кристаллов $\mathrm{LiNbO}_{3}: \mathrm{ZnO}$ униполярность радикально возрастала от $d_{333} \approx 0$ до значения $d_{333} \sim 16.2 \cdot 10^{-12} \mathrm{C} / \mathrm{N}$, что выше верхнего предела значений $d_{333}$ для кристалла $\mathrm{LiNbO}_{3}[15]$, а для монодоменезированных кристаллов $\mathrm{LiNbO}_{3}: \mathrm{ZnO}$ после отжига в закороченном состоянии пьезомодуль $d_{333}$ увеличивался на $15-20 \%[6,7,10]$.

Известно, что вся идеология доменной структуры построена на представлениях о кристалле как об идеальном диэлектрике. Считается, что в монодоменном сегнетоэлектрике энергия деполяризующего поля $\left(E_{d}\right)$, пропорциональная величине спонтанной поляризации $\left(P_{S}\right)$, увеличивает термодинамический потенциал $(G)$. Если это поле не экранируется (например, в объеме кристалла отсутствуют подвижные заряды), то разбиение на домены разрешает парадокс Айзу и оказывается единственным механизмом минимизации термодинамического потенциала $G[1,16,17]$. Последнее есть необходимое условие равновесного состояния кристалла. Однако возникновение доменной структуры дает еще два вклада в потенциал.

1. Доменная стенка имеет конечную толщину и, поскольку в доменах-соседях $P_{S}$ имеет разные направления, возникает большой $\operatorname{grad} P$. Соответствующий вклад в потенциал $\Delta G_{g}$ пропорционален $(\operatorname{grad} P)^{2}$ и при этом $\Delta G_{g}>0[16]$.

2. Второй вклад определяется пьезоэлектрическим эффектом: из-за разнонаправленной $P_{S}$ стенка оказывается механически напряженной. Причем эти напряжение и деформация пространственно неоднородны. В результате механическая энергия доменной стенки тоже дает положительный вклад в потенциал $\left(\Delta G_{m}>0\right)$ [1].

Оба этих эффекта увеличивают термодинамический потенциал. Таким образом, доменная структура как бы „балансирует“ между противоположными тенденциями, 

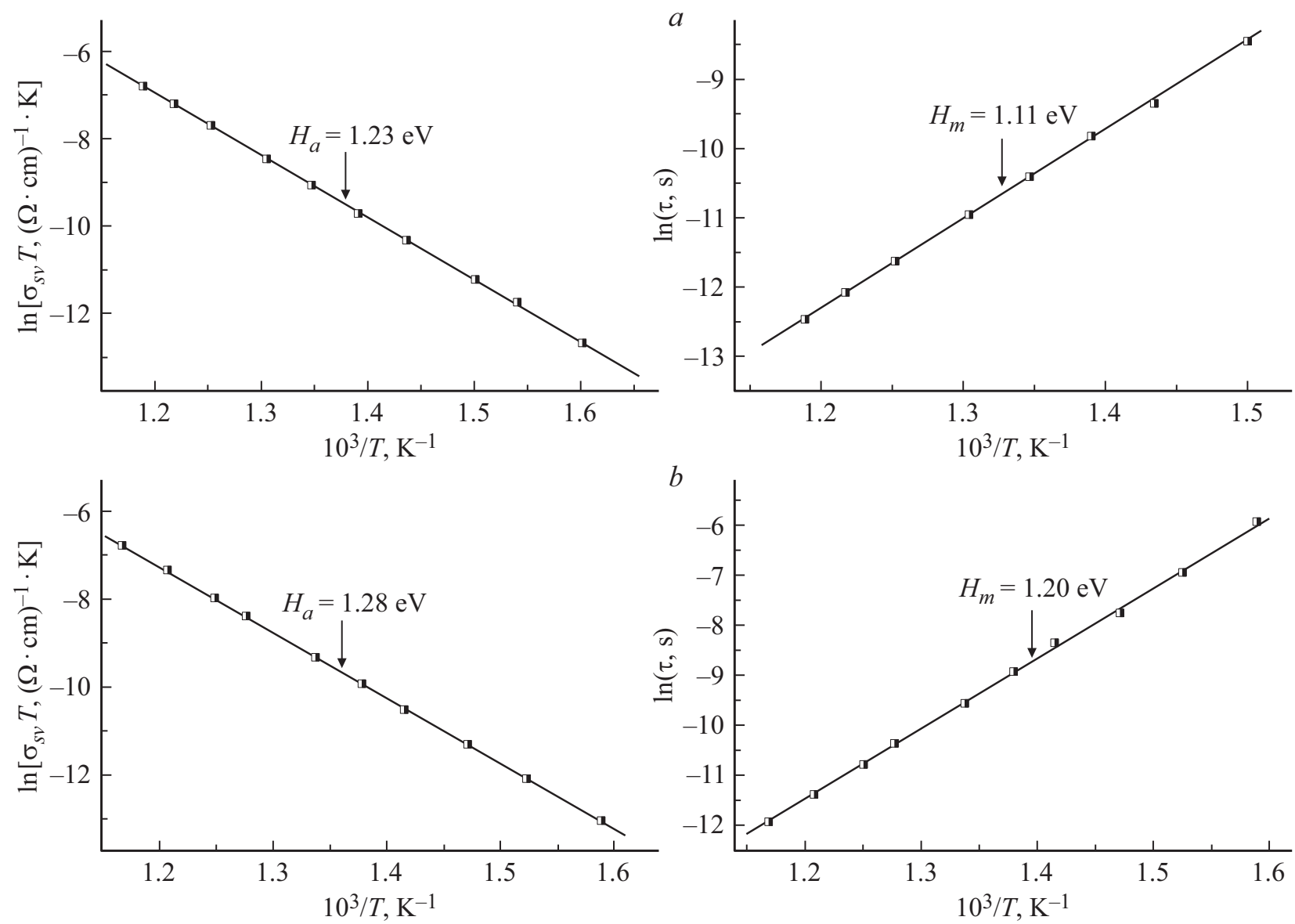

Рис. 3. Температурные зависимости объемной статической проводимости и времени релаксации полидоменного (a) и монодоменизированного $(b)$ номинально чистого кристалла $\mathrm{LiNbO}_{3}$ конгруэнтного состава, z-ориентация.

что и определяет реальные размеры доменов в кристаллах. Если в кристалле появляются условия, позволяющие свести к минимуму деполяризующее поле, то у кристалла не остается никаких термодинамических „мотивов“ к разбиению на домены. Такую возможность предоставляет высокая проводимость, например, высокая статическая проводимость $\sigma_{d c}$, обусловленная подвижными носителями: при $E_{d} \neq 0$ возникает ток с плотностью

$$
j=\sigma_{d c} E_{d}
$$

С течением времени приток свободного заряда компенсирует связанный (поляризационный) заряд, т. е. сводит к минимуму энергию поля $E_{d}$. Очевидно, что этот эффект тем сильнее, чем больше $\sigma_{d c}$. Поэтому, в частности, в сегнетиках с весьма высокой проводимостью (характерный пример - сульфоиодид сурьмы $\mathrm{SbSI})$,электрическая“ доменная структура не возникает вообще [1]. Видно также, что полная компенсация связанного заряда, так же как и образование доменов, восстанавливает симметрию параэлектрической фазы и проблемы с парадоксом Айзу не возникает $[1,17]$.

Эти соображения являются общими для всех сегнетоэлектрических кристаллов, поскольку не связаны с кон- кретной структурой кристалла. Они должны быть справедливы и для кристаллов $\mathrm{LiNbO}_{3}$. В кристаллах $\mathrm{LiNbO}_{3}$ при умеренных температурах вблизи $T_{\text {room }} \sigma_{d c}$ мала, а значения $P_{S}$ и $E_{d}$ сравнительно велики [1-3]. Поэтому очевидно, что описанная картина может наблюдаться только при достаточно высоких температурах. С другой стороны, явление исчезновения доменной структуры, сопровождаемое резким увеличением униполярности, наблюдается для сильно легированных кристаллов $\mathrm{LiNbO}_{3}: \mathrm{ZnO}$ [6-10] и отстутствует, как показано выше, в номинально чистых как исходно полидоменных, так и монодоменизированных кристаллах $\mathrm{LiNbO}_{3}$ конгруэнтного состава (рис. 4). Кристалл $\mathrm{LiNbO}_{3}$ как нестехиометрическая фаза переменного состава, дефицитная по литию, имеет высокую концентрацию антиструктурных дефектов $\mathrm{Nb}_{\mathrm{Li}}$ (катионов $\mathrm{Nb}$, находящихся в позициях катионов Li идеальной стехиометрической структуры) и катионных вакансий в позиции лития $V_{\mathrm{Li}}$ [3]. Такие дефекты практически отсутствуют в структуре сильно легированных кристаллов $\mathrm{LiNbO}_{3}: \mathrm{ZnO}$ или их концентрация сведена к минимуму $[3,18]$. Зато в сильно легированных кристаллах $\mathrm{LiNbO}_{3}$, таких как $\mathrm{LiNbO}_{3}: \mathrm{ZnO}$, формируются заряженные полярные кластеры (комплексные дефекты), состоящие из примесного катиона $\left(\mathrm{Zn}^{2+}\right)$ в 


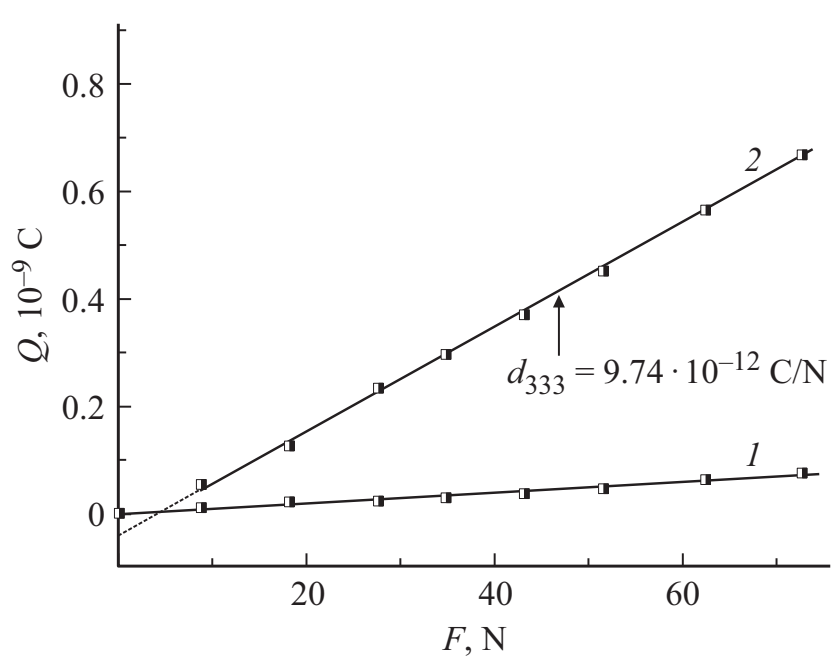

Рис. 4. Зависимости поляризационного заряда от силы, действующей нормально поверхности $\langle 001\rangle, z$-ориентация: 1 - исходно полидоменного номинально чистого кристалла $\mathrm{LiNbO}_{3}$ конгруэнтного состава, $d_{333} \approx 0 ; 2-$ монодоменизированного номинально чистого кристалла $\mathrm{LiNbO}_{3}$ конгруэнтного состава, $d_{333} \approx 9.74 \cdot 10^{-12} \mathrm{C} / \mathrm{N}$. Кристаллы прошли отжиг в условиях короткого замыкания при $T=1270 \mathrm{~K}$ в течение $48 \mathrm{~h}$.

окружении собственных дефектов кристалла, образованных катионами лития, ниобия и вакансиями, положение которых может быть отлично от такового в идеальной стехиометрической структуре $\mathrm{LiNbO}_{3}$ [3]. При этом важную роль в формировании такого кластера могут играть протоны, образующие в структуре кристалла $\mathrm{LiNbO}_{3}$ водородную связь с атомами кислорода [12]. Подобные кластеры могут совершенно по иному стабилизировать доменную структуру кристаллов $\mathrm{LiNbO}_{3}: \mathrm{ZnO}$ по сравнению с номинально чистыми кристаллами $\mathrm{LiNbO}_{3}$. Если домены в кристаллах $\mathrm{LiNbO}_{3}: \mathrm{ZnO}$ имеют заряженные стенки, то при их ликвидации, сопровождаемой распадом стабилизирующих их полярных кластеров, заряд должен выделиться в свободном виде. Это приводит к аномальному скачкообразному поведению зависимостей $\sigma(T)$ и $\varepsilon^{\prime}(T)$ в кристаллах $\mathrm{LiNbO}_{3}: \mathrm{ZnO}$ вблизи температуры $T^{*} \approx 800 \mathrm{~K}$ [6-10]. При этом наличие аномалий на температурных зависимостях $\sigma(T)$ и $\varepsilon^{\prime}(T)$ при вполне определенной температуре $(\sim 800 \pm 10 \mathrm{~K})$ подтверждает, что процесс эволюции доменной структуры запускается, скорее всего, термическим распадом заряженных кластеров, стабилизирующих заряженные доменные границы, что приводит к скачкообразной инжекции дополнительных носителей заряда. Действительно, аномальный скачкообразный рост проводимости в кристаллах $\mathrm{LiNbO}_{3}: \mathrm{ZnO}$ при $T \approx 800 \mathrm{~K}$ приводит к тому, что если при $T<\sim 800 \mathrm{~K}$ проводимость кристаллов $\mathrm{LiNbO}_{3}: \mathrm{ZnO}$ и $\mathrm{LiNbO}_{3}$ практически одинакова, то при $\mathrm{T}>800 \mathrm{~K}$ она выше почти на порядок (рис. 1 и [6-10]). Именно этим, по-видимому, и объясняются отличия в поведении при высоких температурах доменной структуры кристаллов $\mathrm{LiNbO}_{3}: \mathrm{ZnO}$ и $\mathrm{LiNbO}_{3}$.

Вместе с тем компенсация поляризационного заряда свободным зарядом не может произойти мгновенно и имеет определенную кинетику. Кроме того, доменная стенка может быть „закреплена“, помимо полярных кластеров, другими локальными скоплениями точечных дефектов или макродефектами. Это можно представить как потенциальный барьер конечной высоты $H_{D}$, и тогда классическая вероятность его преодоления $\sim \exp \left(-H_{D} / k T\right)<1$. Это объясняет тот факт, что при $T^{*} \approx 800 \mathrm{~K}=$ const исчезновение доменов и соответственно скачок проводимости в кристаллах $\mathrm{LiNbO}_{3}: \mathrm{ZnO}$ развиваются во времени от $\sim 30 \mathrm{~min}$ до нескольких часов [6-10]. Это время, по-видимому, зависит от конкретной конфигурации дефектов, во многом определяемой методом легирования кристаллов [19], а также концентрацией примеси в сильно легированных кристаллах $\mathrm{LiNbO}_{3}$ [6-10].

С другой стороны, если при высокой температуре домены исчезают, то при охлаждении в условиях короткого замыкания до $T_{\text {room }}$ униполярное состояние сохраняется, что сопровождается сохранением увеличенного значения пьезомодуля $d_{333}$ при $T_{\text {room }}$, пропорционального скачку проводимости $\Delta \sigma$ при $T^{*} \approx 800 \mathrm{~K}[10]$. Очевидно, что такое состояние метастабильно. Если ликвидация доменов характеризуется зависящей от температуры кинетикой, то же справедливо и для обратного процесса. Поэтому если охлаждение происходит сравнительно быстро (в нашем случае за $\sim 1.5 \mathrm{~h}$ ), то сохранение

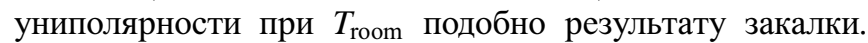
Это не удивительно, поскольку монодоменное состояние кристалла $\mathrm{LiNbO}_{3}$, полученное в результате стандартной монодоменизации, также метастабильно $[1,17]$.

\section{Заключение}

Рассмотрены феноменологические механизмы повышения униполярности при термической обработке сильно легированных кристаллов $\mathrm{LiNbO}_{3}: \mathrm{ZnO}$. Показано, что, когда в кристалле появляются условия, позволяющие свести к минимуму деполяризующее поле (например, приток свободного заряда компенсирует связанный поляризационный заряд и сводит к минимуму энергию деполяризующего поля $E_{d}$ ), происходит распад доменной структуры и соответственно увеличение униполярности кристалла. В кристаллах $\mathrm{LiNbO}_{3}: \mathrm{ZnO}$ процесс эволюции доменной структуры запускается термическим распадом заряженных полярных кластеров, стабилизирующих доменные границы. Это приводит к скачкообразной инжекции дополнительных носителей заряда. При этом аномальный скачкообразный рост проводимости в кристаллах $\mathrm{LiNbO}_{3}: \mathrm{ZnO}$ при $T^{*} \approx 800 \mathrm{~K}$ приводит к тому, что если при $T<800 \mathrm{~K}$ проводимость кристаллов $\mathrm{LiNbO}_{3}: \mathrm{ZnO}$ и $\mathrm{LiNbO}_{3}$ практически одинакова, то при $T>800 \mathrm{~K}$ она выше почти на порядок. 


\section{Конфликт интересов}

Авторы заявляют, что у них нет конфликта интересов.

\section{Список литературы}

[1] Lines M.E., Glass A.M. Principles and Application of Ferroelectrics and Related Materials.: Clarendon Press. Oxford, 1977. $680 \mathrm{p}$.

[2] Кузьминов Ю.С. Ниобат и танталат лития - материалы для нелинейной оптики. М.: Наука, 1975. 223 с.

[3] Сидоров Н.В., Волк Т.Р., Маврин Ю.Н., Калинников В.Т. Ниобат лития: дефекты, фоторефракция, колебательный спектр, поляритоны. М.: Наука, 2003. 255 с.

[4] Shur V.Ya., Rumyantsev E.L., Nikolaeva E.V., Shishkin E.I. // Appl. Phys. Lett. 2000. Vol. 77. N 22. P. 3636-3638. DOI:10.1063/1.1329327

[5] Палатников М.Н., Сидоров Н.В., Калинников В.Т. Сегнетоэлектрические твердые растворы на основе оксидных соединений ниобия и тантала: синтез, исследование структурного упорядочения и физических характеристик. СПб.: Наука, 2001. 2002 (переиздание). 302 с.

[6] Палатников М.Н., Сандлер В.А., Сидоров Н.В., Макарова О.В., Бирюкова И.В., Ефремов И.Н., Иваненко Д.В. // ФTT. 2015. Т. 57. Вып. 8. С. 1515-1520. [Palatnikov M.N., Sandler V.A., Sidorov N.V., Makarova O.V., Biryukova I.V., Efremov I.N., Ivanenko D.V. // Phys. Solid State. 2015. Vol. 57. N 8. P. 1541-1546.] DOI:10.1134/S1063783415080235

[7] Palatnikov M.N., Sandler V.A., Makarova O.V., Sidorov N.V., Manukovskaya D.V., Efremov I.N., Biryukova I.V., Bormanis K. // Integrated Ferroeclectrics. 2016. Vol. 173. N 1. P. 119-127. DOI:10.1080/10584587.2016.1186431

[8] Палатников М.Н., Сандлер В.А., Сидоров Н.В., Макарова O.B. // Неорганические материалы. 2016. Т. 52. № 2. C. 180-186. [Palatnikov M.N., Sandler V.A., Sidorov N.V., Makarova O.V. // Inorganic Materials. 2016. Vol. 52. N 2. P. 147-152.] DOI:10.1134/S0020168516020114

[9] Палатников М.Н., Сандлер В.А., Сидоров Н.В., Бирюкова И.В., Макарова О.В. // Неорганические материалы. 2016. T. 52. № 12. C. 1368-1374. [Palatnikov M.N., Sandler V.A., Sidorov N.V., Biryukova I.V., Makarova O.V. // Inorganic Materials. 2016. Vol. 52. N 12. P. 1291-1296.] DOI:10.1134/S0020168516120086

[10] Палатников М.Н., Сандлер В.А., Сидоров Н.В., Макарова О.В. // Известия СПбГТИ (ТУ). 2016. № 37. С. 75-84.

[11] Niitsu G.T., Nagata H., Rodrigúes A.C.M. // J. Appl. Phys. 2004. Vol. 95. P. 3116-3119. DOI: $10.1063 / 1.1647263$

[12] Volk T.R., Wöhlecke M. Lithium Niobate. Defects, Photorefraction and Ferroelectric Switching. Berlin: SpringerVerlag, 2008. $250 \mathrm{p}$.

[13] Jonscher A.K. Dielectric relaxation in solids. CD London: Press Ltd, 1983.

[14] Хладик Джс. Физика электролитов. М.: Мир, 1978. 556 с.

[15] Акустические кристаллы. Справочник: / Под ред. М.П. Шаскольской. М.: Наука, 1982. 632 с.

[16] Струков Б.А., Леванюк А.П. Физические основы сегнетоэлектрических явлений в кристаллах. М.: Наука, 1983. $240 \mathrm{c}$.

[17] Барфут Джс., Тейлор Джс. Полярные диэлектрики и их применения. / Пер. с англ. под ред. Л.А. Шувалова, М.: Мир, 1981.
[18] Palatnikov M.N., Sidorov N.V., Manukovskaya D.V., Makarova O.V., Aleshina L.A., Kadetova A.V. // J. American Ceramic Society. 2017. Vol. 100. N 8. P. 3703-3711. DOI: 10.1111 jace.14851

[19] Palatnikov M.N., Birukova I.V., Masloboeva S.M., Makarova O.V., Manukovskaya D.V., Sidorov N.V. // J. Crystal Growth. 2014. Vol. 386. P. 113-118. DOI: $10.1016 /$ j.jcrysgro.2013.09.038 